\title{
CONTROLE DA QUALIDADE APLICADO NO SETOR DE HORTIFRÚTI DE UM SUPERMERCADO COMO ESTRATÉGIA PARA ATENUAÇÃO DE PERDAS
}

\section{QUALITY CONTROL APPLIED ON THE FRUIT AND VEGETABLE SECTOR OF A SUPERMARKET AS A STRATEGY FOR LOSS ATTENUATION}

\author{
Beatriz Martins Pereira; Graciele Priscila de Oliveira Bravin; Andreia de \\ Menezes Olivo
}

Universidade do Oeste Paulista - UNOESTE, Faculdade de Engenharia, Curso de Engenharia de Produção, Presidente Prudente, SP.

E-mail: bia martins260597@hotmail.com

RESUMO - A presente investigação tem como objetivo atenuar as perdas e minimizar custos no setor de hortifrúti de um supermercado varejista aplicando as ferramentas da qualidade. Realizou-se um levantamento das perdas do setor, aplicando as ferramentas da qualidade para diagnóstico da origem do problema e tomada de decisão, e por fim foi realizada uma análise dos dados com o intuito de propor a metodologia adequada para a solução do problema. A pesquisa foi de natureza quali-quantitativa com caráter exploratório tendo como método de investigação o estudo de caso. Como instrumento para a coleta de dados foi utilizada a pesquisa bibliográfica, pesquisa documental e observação. Os resultados obtidos mostraram que os fatores que provocam ou auxiliam o aumento das perdas são o excesso de umidade relativa do ar, transporte, manuseio incorreto ou excessivo e acondicionamento não adequado.

Palavras-chave: controle; estratégia; redução de perdas; ciclo PDCA; melhoria contínua.

ABSTRACT - This present research aims to reduce losses and minimize costs in the fruit and vegetables sector of a retail supermarket applying the quality tools. A survey of the losses of the sector was carried out, applying the quality tools to diagnose the origin of the problem and decision making, and finally a data analysis was carried out with the purpose of proposing the appropriate methodology for the solution of the problem. The research was of qualitative-quantitative nature with exploratory character having as investigation method the case study. As a tool for data collection, bibliographical research, documentary research and observation were used. The results obtained showed that the factors that provoke or help increase the losses are the excess of relative humidity of the air, transport, incorrect or excessive handling

Recebido em: 28/10/2017 Revisado em: 27/02/2018 Aprovado em: 06/03/2018 and inadequate packing.

Keywords:control; strategy; loss reduction; PDCA cycle; continuous improvement. 


\section{INTRODUÇÃO}

O varejo brasileiro em 2014 perdeu em média $2,89 \%$ de seu faturamento líquido em virtude de furtos, roubos e quebras operacionais de acordo com análises e pesquisas realizadas em 2015 pela Associação Brasileira de Supermercados (ABRAS). Segundo pesquisas realizadas pelo Instituto Brasileiro de Varejo e Mercado de Consumo (IBEVAR) e pelo Programa de Administração de Varejo (PROVAR), o índice de perdas de faturamento do varejo brasileiro em 2014 apresentado pelo ABRAS foi de $2,89 \%$, pode ser observado que este valor apresentou-se maior que o registrado globalmente, valor este de $1,36 \%$, e maior também para as perdas observadas em lugares como América do Norte (1,49\%), Europa (1,27\%) e América Latina (1,60\%). 0 segmento com maior representatividade nessas perdas são as pequenas e médias empresas com 4,44\%, seguido pelos supermercados com 2,98\%, as lojas de material de construção com $1,72 \%$ e as drogarias com 0,38\% (ABRAS, 2015).

Com relação ao supermercado, segmento escolhido para esse estudo, $35,02 \%$ das empresas não possuem uma área para prevenção de perdas. As suas principais causas são quebras operacionais com $33,35 \%$, erros de inventário (16,59\%), furtos externos $(16,03 \%)$ e internos $(8,64 \%)$. E os setores que apresentam maior índice de perdas são os de frutas, legumes e verduras (FLV) com 8,29\%, padaria e confeitaria $(5,58 \%)$, peixaria $(4,35 \%)$ e açougue $(4,24 \%)$ (ABRAS, 2015).

São inúmeros os fatores que acarretam essas perdas e quebras, como o mau planejamento do setor de compras e vendas, seleção de fornecedores, danos no transporte e recebimento, forma de armazenagem, exposição do produto e manuseio impróprio.

Perante essas circunstâncias, surge a proposta de ações de melhorias visando minimizar as perdas aplicando o controle de qualidade no setor de hortifrúti de um supermercado. As perdas são recorrentes da diferença entre o estoque físico e contábil, ou seja, quando não é possível identificar a causa. As quebras são alimentos descaracterizados comercialmente, prazo de validade expirado ou consequência da má gestão dos produtos na empresa. É importante ressaltar que podem ocorrer dois tipos de quebras, os que são destinados ao lixo, alimentação animal e adubo por estar impróprio para o consumo humano e os que são considerados sobras, que não estão com boa aparência para serem vendidos, porém estão aptos para o consumo.

Para realizar o gerenciamento da empresa pelo controle de qualidade é imprescindível a utilização das sete ferramentas básicas da qualidade, sendo elas: as folhas de verificação, a estratificação, as cartas controle, os gráficos de dispersão, os diagramas de causa-efeito, os diagramas de Pareto e os histogramas. Para o emprego correto dessas ferramentas é usado a Metodologia de Análise e Solução de Problemas (MASP) que tem como base o ciclo Planejar, Executar, Verificar e Agir (PDCA).

Diante deste cenário, este artigo tem como objetivo principal aplicar as ferramentas da qualidade desenvolvidas para auxiliar no controle de qualidade para produção de bens e serviços como a folha de verificação; histograma; diagrama de Pareto; diagrama de causa e efeito/Ishikawa; diagrama de dispersão e gráfico de controle, em busca de mensurar e minimizar as perdas ocorridas no setor de hortifrúti de uma rede de supermercados e propor uma metodologia para solução os problema de perdas deste setor.

\section{METODOLOGIAS DA QUALIDADE}

De acordo com Mello (2011, p.67) "o ciclo PDCA propõe a análise dos processos com vistas a sua melhoria". Seleme e Stadler (2010, p.27) também seguem a mesma linha de raciocínio quando define o PDCA da seguinte maneira "[...] método de melhoria contínua, não esgota sua aplicabilidade com uma única utilização no processo, visto que implementa na organização uma cultura de 
melhoria que permeia todos os processos". Segundo os autores, a metodologia possui quatro etapas como visto a seguir:

- $\quad$ Planejar (plan): definir quais os objetivos de melhorias que desejam alcançar e os métodos que utilizarão para atingirem;

- Executar (do): realizar treinamentos e executar as atividades que foram planejadas para alcançar os objetivos;

- Verificar (check): examinar os resultados obtidos e comparar com os que foram estabelecidos, caso haja variação dos resultados obtidos com os planejados, devese propor mudanças;

- Agir (action): através da análise feita anteriormente, deve-se realizar as correções das variações de acordo com os parâmetros definidos ou, propondo novos padrões.

"Se o ciclo PDCA segue em direção à melhoria contínua, o Masp o utiliza para realizar a análise do problema e para validar a solução proposta, quando de sua formulação" (SELEME; STADLER, 2010, p.29). De acordo com Gozzi (2015, p.41) "A MASP tem como principal foco a identificação dos problemas e, consequentemente, a definição de ações corretivas e preventivas a fim de eliminar ou minimizar os problemas detectados". Com base nas definições dos autores e na definição da metodologia MASP, conclui-se que a mesma auxilia os gestores na identificação do problema e na formulação do plano de ação, utilizando como princípio o ciclo PDCA para direcionar os procedimentos.

\subsection{Ferramentas da Qualidade}

Para a implantação das metodologias, torna-se necessário a utilização das sete ferramentas da qualidade. Vieira $(2012$, p.5) afirma que "As sete ferramentas estatísticas para o controle da qualidade são um conjunto de técnicas gráficas que permitem resolver boa parte dos problemas estatísticos que surgem no decorrer da análise de dados quando a intenção é manter a qualidade". Tais ferramentas serão apresentadas a seguir (SELEME; STADLER, 2010; VIEIRA, 2012; MENEZES, 2013).
- Folha de Verificação: é um documento em formato de tabela ou planilha para registrar anotações e dados, de forma organizada e norteada para o problema ou circunstâncias que se deseja resolver. Ela permite o registro de informações advindas de observações praticadas durante a execução dos processos. Esta ferramenta normalmente é a primeira a ser utilizada nas metodologias de solução de problemas. Proporciona coletas de dados rápidas e simples, economizando tempo e evitando anotações informais que são perdidas.

- Estratificação: é uma técnica de divisão de grupos em subgrupos de dados agrupados/classificados em relação a atributos, características, categorias ou qualquer outro fator semelhante e significativo para coleta e análise. Quando dados de produtos fabricados com materiais oriundos de diversas origens (como diversos fornecedores) ou de circunstâncias diferentes (diferentes máquinas ou operadores) são agrupados em um só conjunto, a variação pode se tornar impossível de entender, e com o uso da estratificação possibilita-se a verificação por partes menores, até que se encontre a causa principal dos problemas.

- Histograma: é um gráfico de colunas que demonstram a distribuição de um conjunto de dados. A forma dessa distribuição possibilita identificar a natureza e origem das informações. Através do estudo dessa forma é possível reconhecer o tipo de distribuição de frequência e a existência de anomalias causadoras de visíveis distorções. Outro parecer que pode ser extraído dessa ferramenta é a tendência central, isto é, onde tem um maior agrupamento de dados. Com isso pode-se obter a média, mediana ou moda. Ela também permite observar a dispersão entre os dados. Como medida dessa variabilidade é utilizado o desvio padrão.

gráfico de barras desenvolvido para apresentar as causas de variação por ordem decrescente de frequência. Seu princípio é conhecido pela proporção "80/20", ou seja, a 
maior parte dos problemas procede de um número pequeno de causas, logo se estas forem identificadas e eliminadas, quase todos os problemas também serão.

$$
\text { - Diagrama de causa e }
$$
efeito/Ishikawa: é uma representação gráfica que auxilia na identificação das causas que fazem com que o problema ocorra e põe em ordem as ideias sugeridas em categorias. Essas causas são caracterizadas pelo chamado 6Ms (método, mão de obra, materiais, máquina, meio ambiente $\mathrm{e}$ medição), que são denominadas causas primárias, pois delas provém a maior parte dos problemas.

- Diagrama de dispersão: é um gráfico que demonstra a relação entre duas variáveis. Pode ser utilizado para verificar a relação do problema com determinada causa estabelecida no diagrama de causa e efeito, confirmar a tese que duas variáveis são relacionadas e proporcionar o nível de força dessa relação.

- Gráfico de controle: é utilizado para controlar o comportamento do processo ao longo do tempo. Ele serve para demonstrar a variabilidade que normalmente ocorre no processo, para apurar se o processo está sob controle, identificar causas especiais de variação e verificar se as melhorias realizadas resultaram em menor variabilidade no processo.

Além das sete ferramentas básicas da qualidade, existem várias outras. Duas delas são o brainstorming e $5 \mathrm{~W} 2 \mathrm{H}$, que auxiliam na solução de problemas. Segundo Seleme e Stadler (2010), o brainstorming é uma ferramenta empregada em reuniões onde os participantes tem autonomia para expor suas ideias, por mais improváveis que pareçam ser.

\section{GESTÃO DE DEMANDA}

Os processos produtivos têm como objetivo atender as demandas do mercado. Para Bezerra (2014) pode-se conceituar demanda como a quantia de bens e serviços os que os clientes querem obter, ao longo do tempo. Possuindo uma noção dessa quantidade, a empresa torna-se capaz de se adaptar, a fim de atender a demanda, quando esta for concretizada. Segundo Slack, Chambers e Johnston (2009) existem dois tipos de demanda: a dependente, ou seja, possui relação com outro produto, consequentemente pode-se considerar uma demanda provável; e a independente, que está relacionada com o produto final. Por isso, não consegue definir a demanda de forma precisa, devido aos diversos fatores.

Para Slack, Chambers e Johnston (2009), a gestão da demanda abrange diversas tarefas que fazem a comunicação da empresa com o mercado. Pode fazer parte dessas tarefas o registro de pedidos, a previsão de demanda, o compromisso com a entrega, o serviço de atendimento ao cliente e a distribuição da compra. Para auxiliar o planejamento é utilizada a carteira de pedidos, onde os vendedores registram os pedidos já confirmados pelos consumidores e a previsão de vendas, sendo estas baseadas em dados históricos. Combinando as informações adquiridas dessas duas fontes, é encontrada a demanda da empresa.

Santos (2015) afirma que para executar a previsão de demanda, é imprescindível ter conhecimento de seus dados históricos, de variáveis que os influenciam e informações sobre efeitos que acarretam desempenho anormal. Também é importante ter noção sobre a economia, comportamento dos concorrentes e definições do setor comercial da empresa. Assim como Santos (2015), Slack, Chambers e Johnston (2009) relatam existir dois métodos para previsão: o qualitativo, baseado em interpretações, opiniões, experiências e pesquisa de satisfação do cliente; e o quantitativo, que aplica modelos matemáticos e estatísticos para analisar as tendências e correlação das causas, a fim de realizar as previsões.

\section{GESTÃO DE COMPRAS}

O setor de compras é encarregado a exercer a comunicação entre a organização e o ambiente externo, proporcionando a entrada dos itens necessários. O processo de 
compras abrange o desenvolvimento e seleção de fornecedores, adquirir os materiais com melhor preço e forma de pagamento e controlar todo o processo de modo a receber tudo dentro das especificações exigidas. (CHIAVENATO, 2014). "Contudo, a gestão de compras não se limita ao ato de comprar e monitorar. É um processo estratégico, que envolve custo, qualidade e velocidade de resposta. É uma tarefa crucial para a organização, seja de que tipo for" (BERTAGLIA, 2003 apud NACK; BONFADINI, 2013, p. 147).

Para uma administração ser eficaz é necessário executar um bom planejamento e controle. Siqueira (2013) afirma que para isso deve atender objetivos como: sustentar um estoque baixo, eliminar itens não conformes do estoque, não admitir situações que acarretem falta ou excesso de produtos, precaver-se contra roubos, perdas ou mau uso, possuir escala de produtos compatível com a necessidade, conceder históricos para planejamento estratégico, tático, operacional e buscar atingir o menor custo.

\section{METODOLOGIA}

Para desenvolver a pesquisa, foi adotado o estudo de caso utilizando a abordagem combinada ou quali-quantitativa. De forma a justificar esta escolha, a abordagem quantitativa foi aplicada na etapa de coleta de dados, onde foram coletadas por meio de folhas de verificação. Havendo a preocupação com a análise e quantificação das perdas, foi feita a coleta das variáveis que as influenciam, nos respectivos setores no qual o estudo se aplicará. Por meio da aplicação de gráficos de Pareto e gráfico de dispersão, os dados coletados foram analisados e verificados no que se refere à correlação entre as causas e o efeito por meio da abordagem estatística.

Os critérios de cunho qualitativo partiram de uma observação desenvolvida pela pesquisadora na organização, com o intuito de entender melhor o processo e em consulta de dados históricos, na busca de se realizar uma discussão comparativa referente às perdas existentes nos setores, desse modo possibilitando o melhor entendimento da natureza das variáveis a fim de desenvolver argumentos e propor soluções para a problemática.

\section{RESULTADOS}

A partir de observações e levantamentos, foi criada a folha de verificação que apresentou as perdas nos meses delimitados pelo estudo.

Com os dados coletados por esta ferramenta da qualidade, que são as folhas de verificação, foi possível uma análise por Pareto trimestral no período de 2015 e 2016, como mostra as Figuras de 1 a 4. Esta análise resultou nas seguintes observações pelas autoras da pesquisa.

O primeiro trimestre de 2015 apresentou um total de quebra de $19.548,740 \mathrm{Kg}$, representando $6,35 \%$ das vendas do setor nesse trimestre. Os itens que compõe os $80 \%$ de quebra respectivamente são: laranja, tomate rasteiro, batata extra, mamão formosa, limão, maça gala, mamão papaia, maça fuji, abacaxi hawai, banana maça, cebola, berinjela, banana prata, manga, goiaba, melancia, cenoura, repolho, chuchu, laranja lima e pêssego, representando frutas, legumes e tubérculos. 
Figura 1. Quebras Hortifrúti - 10 Trimestre/2015

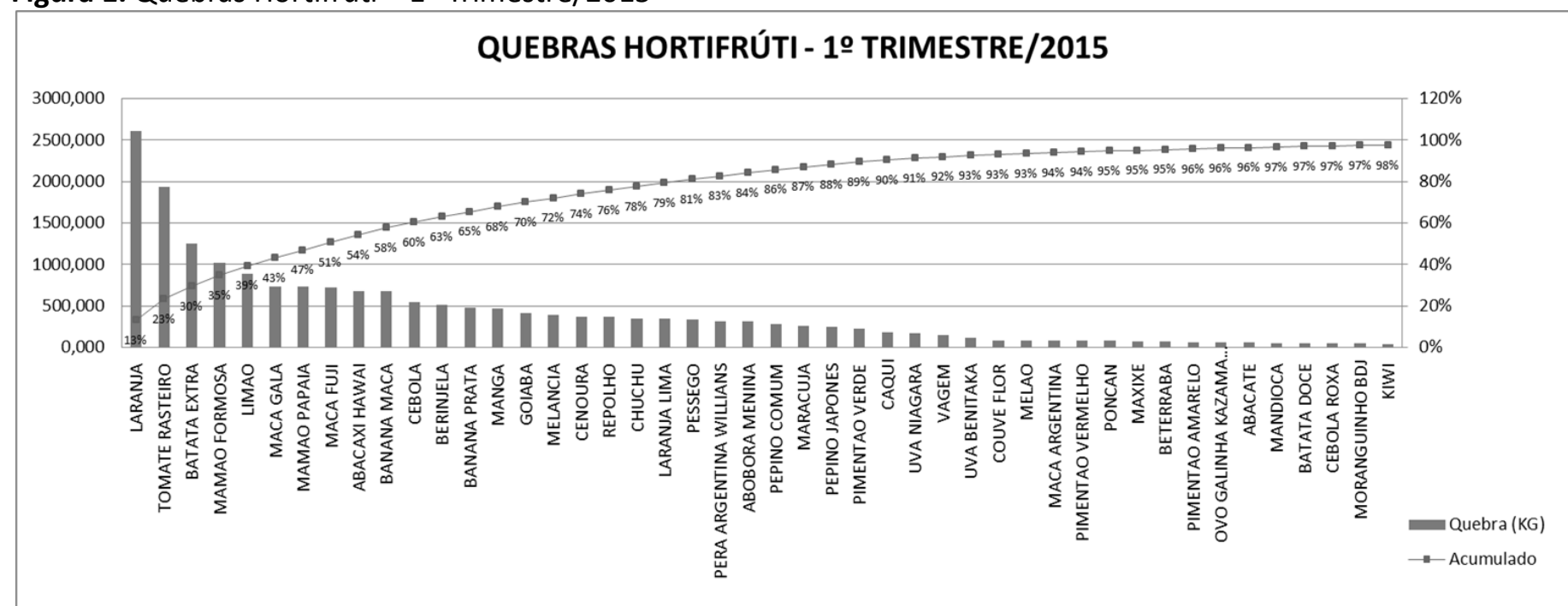

Fonte: OAutor.

Em contrapartida, o primeiro trimestre de 2016 teve um total de quebra de $13.888,559 \mathrm{Kg}$, representando $5,33 \%$ das vendas do setor no respectivo trimestre. Os produtos que representam $80 \%$ das quebras na devida ordem são: tomate rasteiro, laranja,batata extra, cebola, banana nanica, mamão papaia, mamão formosa, melancia, banana prata, pêssego, laranja lima, limão, banana maça, manga, repolho, maça fuji, abacaxi hawai, cenoura, goiaba, maça gala, pêra.

Figura 2. Quebras Hortifrúti - 1o Trimestre/2016

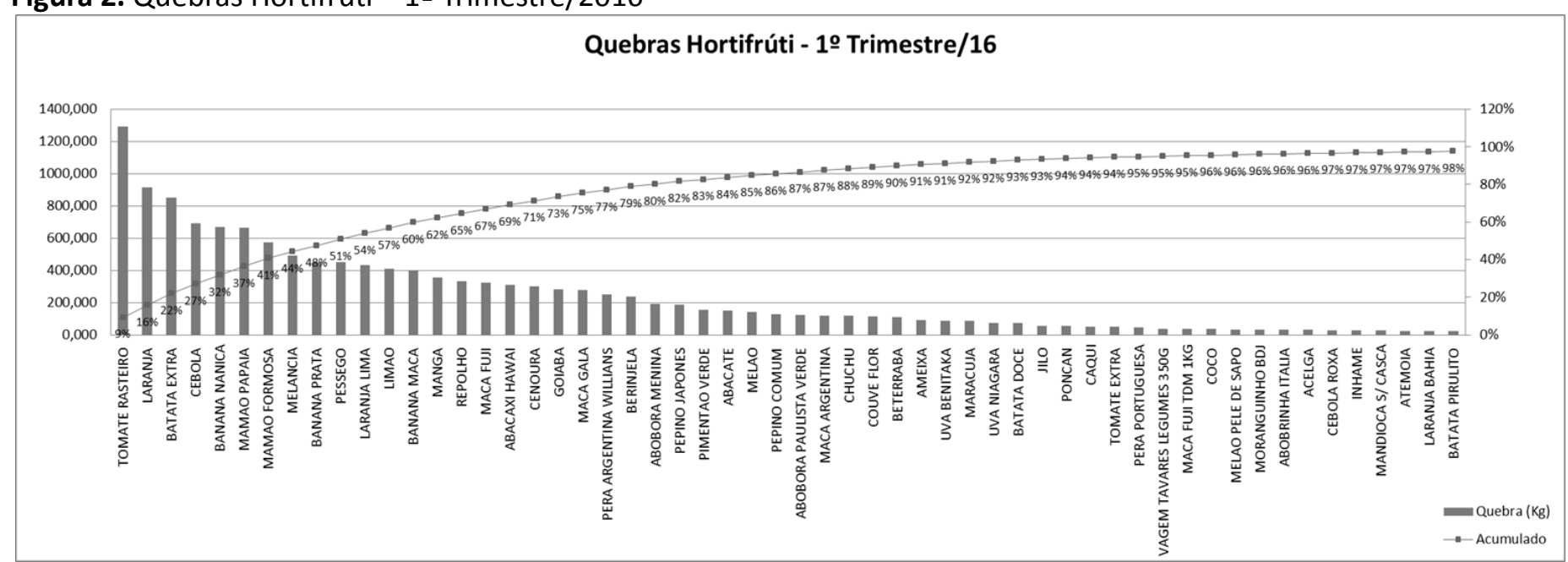

Fonte: O Autor.

No segundo trimestre de 2015 obteve-se um total de quebra de $15.637,390 \mathrm{Kg}$, representando $5,21 \%$ das vendas do setor nesse trimestre. Os itens que compõe os $80 \%$ de quebra respectivamente são: poncan, mamão formosa, laranja, batata extra, maça gala, mamão papaia, melancia, tomate rasteiro, cebola, maça fuji, limão, abacaxi hawai, caqui, berinjela, pera argentina. 
Figura 3. Quebras Hortifrúti - 2o Trimestre/2015

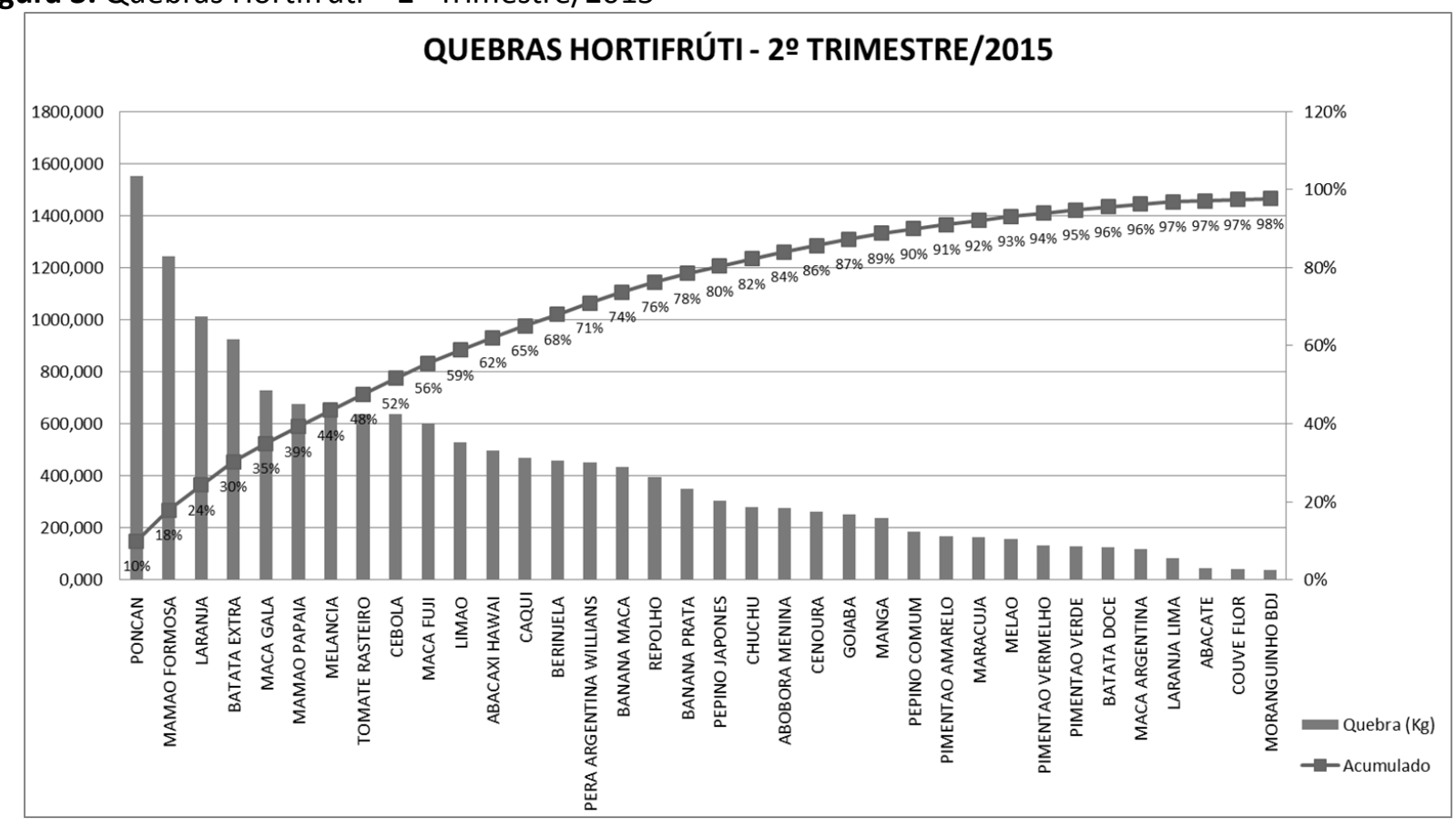

Fonte: O Autor.

No mesmo período do ano 2016, o setor apresentou um total de quebra de $12.278,648 \mathrm{Kg}$, representando $5,11 \%$ das vendas do hortifrúti nesse trimestre. Os itens banana nanica, tomate rasteiro, poncan, batata extra, laranja, cebola, mamão formosa, abacaxi hawai, repolho, berinjela, maça gala, goiaba, pepino japonês, melancia, limão, cenoura, banana prata, pera, argentina willians, banana maça, maça fuji, caqui e abobora menina, representaram $80 \%$ das quebras.

Figura 4. Quebras Hortifrúti - 2o Trimestre/2016

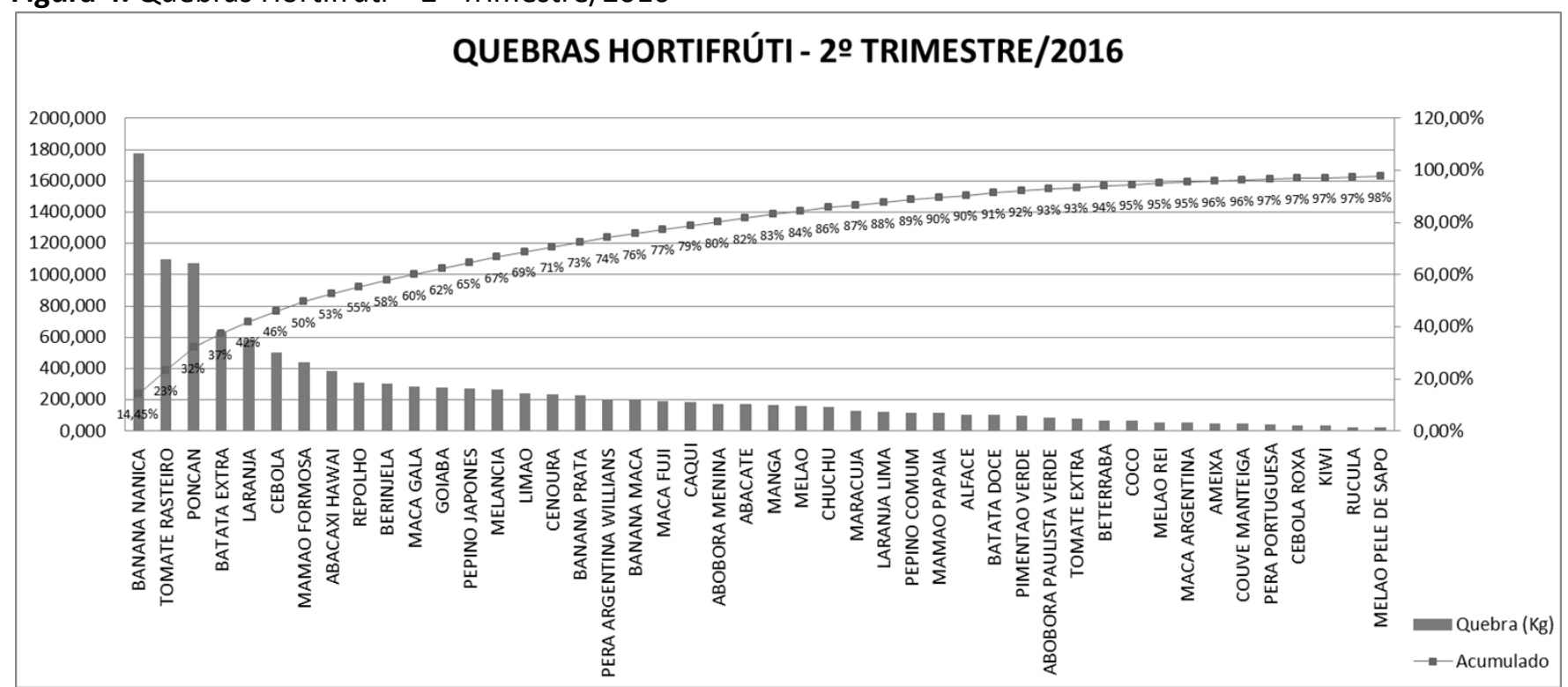

Fonte: O Autor. 
Foi realizado um brainstorming com alguns funcionários do supermercado. A equipe que compôs esta atividade foi formada por pessoas que são peças chave no processo de gerenciamento de compras e operações. $O$ efeito principal do brainstorming foi constatar as possíveis causas que acarretavam as perdas de cada um desses produtos.

Com o intuito de entender e expor tudo que foi levantado, utilizou-se a ferramenta diagrama de causa e efeito para organizar as origens das perdas de acordo com suas respectivas categorias. Uma vez que a mesma possibilita que o grupo mantenha-se focado nas causas e não mais nos efeitos.

Figura 5. Diagrama de Ishikawa para determinação das causas primárias.

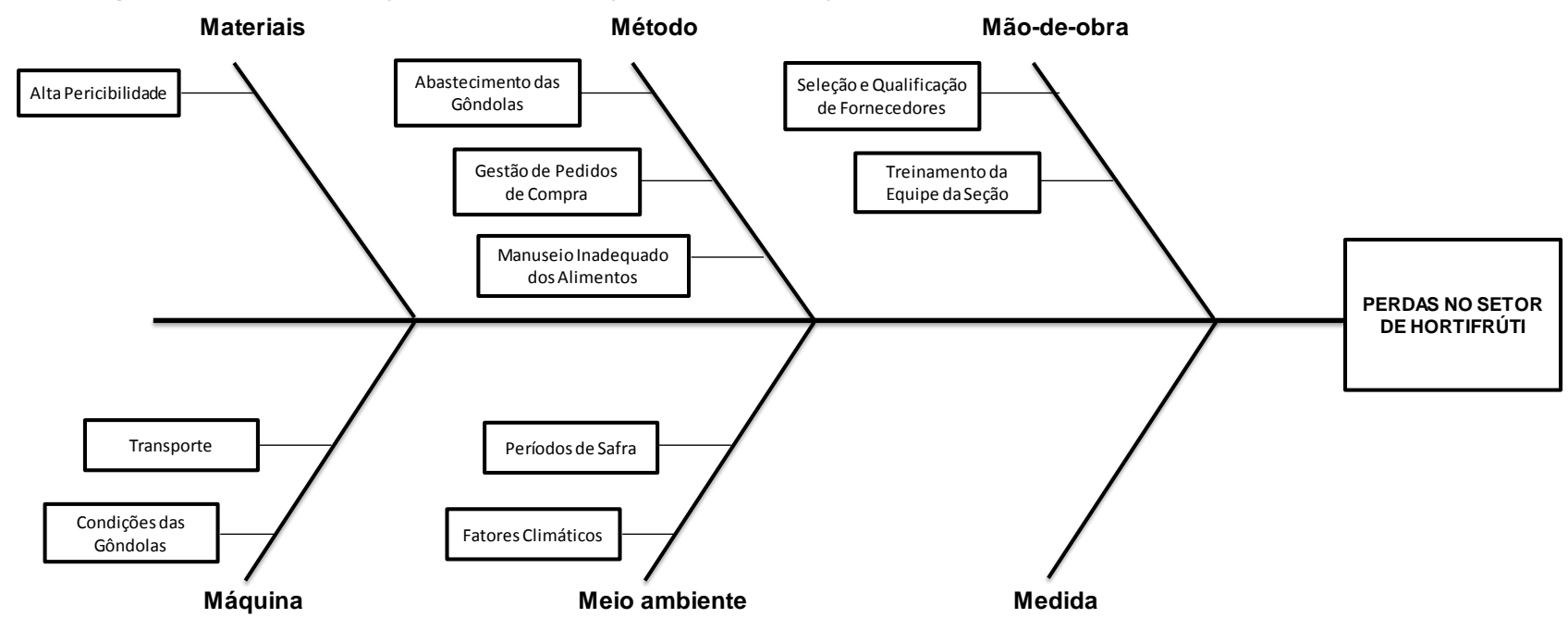

Fonte: O Autor.

Em materiais a causa primária listada foi a alta perecibilidade de grande parte dos produtos, ela está ligada a ação dos microrganismos, os quais causam alterações químicas desfavoráveis, implicando em deteriorações, essas deteriorações modificam as características dos alimentos, como a pigmentação, o odor, o gosto e sua consistência. Para o desenvolvimento desses microrganismos, é necessário que haja situações benéficas, como os fatores intrínsecos e extrínsecos ao produto.

Um fator intrínseco aos alimentos é a atividade da água (Aa). Os microrganismos necessitam de presença de água para seu desenvolvimento e metabolismo, as bactérias são as que mais precisam dessa subsistência, em seguida as leveduras e bolores. Outra condição é o potencial de oxidorredução (Eh), determinado como a capacidade que o substrato tem de ganhar (redução) ou perder (oxidação) elétrons, sendo o oxigênio o elemento que tem maior contribuição para o aumento do potencial de oxidorredução de um alimento.

A estrutura biológica também é considerada um fator intrínseco, alguns alimentos possuem coberturas físicas que as protegem da entrada e desenvolvimento de microrganismos, como por exemplo, as cascas das frutas e dos vegetais. Porém, quando essas coberturas são danificadas, permitem que os microrganismos contaminantes penetrem nos tecidos subjacentes repletos de nutrientes, propiciando assim seu desenvolvimento e conseguinte deterioração.

Outro fator intrínseco muito importante nas análises de perdas dos itens do hortifrúti é o $\mathrm{pH}$. O grau de acidez dos produtos influencia no crescimento e metabolismo dos microrganismos, os 
alimentos com pH maior que 4,5 são considerados pouco ácidos, entre 4,0 e 4,5 ácidos e menos que 4,0 muito ácidos. A maior parte dos microrganismos se desenvolvem em $\mathrm{pH}$ próximos a 7,0.

Entretanto, em uma faixa de $\mathrm{pH}$ de 6,0 a 8,0 é mais propício o desenvolvimento das bactérias. As leveduras propagam-se na escala de pH de 4,5 a 6,0. Nessa escala está a maior parte dos itens perdidos por alta perecibilidade, como a abóbora $(4,8-5,2)$, batata $(5,3-5,6)$, berinjela $(4,5)$, cebola $(5,3-$ $5,8)$, cenoura $(4,9-5,2 ; 6,0)$, banana $(4,5-4,7)$ e melancia $(5,2-5,6)$. E os bolores e mofos se desenvolvem em $\mathrm{pH}$ entre 3,5 e 4,0, como por exemplo no pepino que possui um $\mathrm{pH}$ de 3,8 , na laranja $(3,6-4,3)$ e no tomate $(4,2-4,3)$.

$\mathrm{O} \mathrm{pH}$ mais ácido das frutas, como da maça $(2,9-3,3)$ e do limão $(1,8-2,0)$ impede o crescimento bacteriano, sendo os bolores e as leveduras os agente de deterioração mais significativos. Entre os diversos parâmetros extrínsecos que contribuem para 0 crescimento de microrganismos, a temperatura é a que tem maior influencia. Quatro grupos foram estabelecidos em relação as faixas de temperatura em que as bactérias se desenvolvem: termófilos, mesófilos, psicrófilos e psicotróficos.

Como os produtos do setor de hortifrúti ficam expostos em temperatura ambiente, o grupo de microrganismos que tem mais tendência a se desenvolver é os mesófilos com temperatura ótima entre 30 a $45^{\circ}$ C. Entre os mesófilos estão às bactérias patogênicas, deterioradoras, bolores e leveduras. A velocidade especifica de crescimento é reduzida na medida em que a temperatura se afasta do valor ótimo. Outro parâmetro extrínseco é a umidade relativa do ambiente, que influencia a atividade da água (Aa). Quando armazenado um alimento de baixa atividade de água em local de alta umidade, o valor da Aa aumentará, ocasionando deterioração.

É sabido que existem relações entre a atividade da água ( $\mathrm{Aa}$ ), a temperatura e os nutrientes. Independente da temperatura, o desenvolvimento dos microrganismos diminui na proporção em que diminui a atividade da água. $\mathrm{Na}$ temperatura ótima de desenvolvimento, a atividade da água é maior. E a presença de nutrientes faz com que o limite de atividade da água aumente, favorecendo a sobrevivência dos microrganismos. Da mesma forma, deve-se considerar a relação entre a atividade da água, a temperatura e o $\mathrm{pH}$.

$\mathrm{Na}$ categoria método, as causas primárias são: abastecimento das gôndolas, gestão de pedidos de compra e manuseio inadequado dos alimentos. $O$ procedimento de abastecimento das gôndolas pode gerar quebras quando colocado produtos em excesso, ou seja, fizer um empilhamento muito alto e através da forma do abastecimento, o produto não pode sem jogado na gôndola, deve ser colocado de forma correta para não danificá-lo.

No abastecimento é importante considerar a qualidade e não a quantidade. Deve-se estar monitorando a seção em um intervalo de tempo pré-determinado, a fim de não deixar faltar produto na gôndola $\mathrm{e}$ retirar os que estão danificados. Abastecer mais vezes durante o dia fará com que haja uma diminuição das perdas. Também é necessário que verificar a temperatura e umidade do ambiente em que os produtos estão expostos.

A qualidade da gestão de pedidos de compra afeta diretamente todo o fluxo das vendas. Quando o pedido é feito em excesso, gera perdas por maturação excessivas das sobras e quando é escasso, ocasiona rupturas nas gôndolas e perdas nas vendas. Um bom pedido é aquele que está mais próximo dos parâmetros reais. Para estabelecer o quanto e quando comprar é preciso levar em consideração a quantidade em estoque, a venda média no período, variações da média das vendas e o prazo de entrega do fornecedor.

O manuseio inadequado e em excesso podem retirar a cera natural das frutas que as protegem da perda de água. Além de acarretar lesões na superfície dos produtos que permitem os microrganismos e enzimas 
acelerarem 0 processo de podridão. Portanto, o manuseio tanto por parte dos funcionários da seção em todas as fases do processo, ou por parte dos clientes, e causador de uma parcela das perdas.

$\mathrm{Na}$ categoria mão de obra as causas primárias são: seleção e qualificação de fornecedores e treinamento da equipe da seção. Todos os participantes da cadeia são responsáveis pela a redução de perdas, começando pelo produtor. A qualidade dos produtos é definida durante o plantio e o manejo. Dessa forma antes de determinar um fornecedor de FLV, é necessário que o mesmo atenda ao critério de qualidade, processo produtivo, análise de resíduos químicos, análise microbiológica, padronização/ embalagem, logística, preço e desconto/ bonificação.

As quebras podem ser reduzidas por meio do conhecimento e trabalho. Desse modo é de extrema relevância o treinamento da equipe de FLV. É preciso padronizar os processos, ou seja, definir o que e como fazer cada tarefa. Os funcionários devem ser conscientizados sobre a importância de alcançar menores índices de perdas.

As causas primárias listadas para máquina foram transporte e condições das gôndolas. $\mathrm{Na}$ etapa de transporte dos produtos, há diversas variáveis que influenciam nas perdas, como: veículo inadequado, a acomodação em embalagens inapropriadas, manuseio excessivo e incorreto na carga e descarga, as trepidações na estrada e o contato com outros produtos estragados. Outro fator agravante é a má higienização dos caminhões, que contribuem diretamente para o desenvolvimento de microrganismos.

As gôndolas utilizadas para exposição dos produtos FLV são de MDF, esse material não é recomendado para ficar em contato com os alimentos. Os equipamentos utilizados para exposição devem ser fáceis de higienizar e não podem transferir substâncias tóxicas, gosto e cheiro. A limpeza e higienização desses locais devem ser constantes. Todas as vezes que ocorrer retirada e troca de mercadoria, é recomendado utilizar água, sabão neutro e solução clorada para higienizar aquele local.

As causas relacionadas à categoria meio ambiente não estão sob controle do ser humano, sendo o período de safra e os fatores climáticos. Os produtos em época de safra possuem uma melhor qualidade e uma maior produtividade, consequentemente terá um preço menor. Dessa forma os produtos vendidos fora do período de safra têm variações de preço e uma menor qualidade, acarretando na diminuição de compra dos clientes e quebras.

O fator climático é a variável de maior influência na produção agrícola. Ele interfere em todas as etapas da cadeia de produção, como plantio, colheita, armazenagem, transporte e comercialização. Os elementos que compõe o fator climático são: radiação solar, umidade, chuva, temperatura e velocidade do vento. Ambientes desfavoráveis podem acarretar a diminuição da produtividade e aumento de pragas, consequentemente reduzirá a qualidade dos produtos. É importante considerar a estação na hora da compra, ou seja, no inverno devese comprar o produto maduro e no verão um pouco mais verde, pois o mesmo irá amadurecer com o clima.

No que se refere às práticas de controle de qualidade, o presente trabalho tem como proposta a implantação de procedimentos operacionais padronizados, avaliação de fornecedores e previsão de vendas a fim de eliminar ou minimizar as perdas do setor de hortifrúti do supermercado. O objetivo da implantação do procedimento operacional padrão é atuar diretamente sobre $\mathrm{o}$ abastecimento das gôndolas e manuseio inadequado dos alimentos. A criação destes procedimentosirá orientar as sequências das atividades e a periodicidade de realização, apresentando os seguintes elementos: o encarregado pela realização e os equipamentos, materiais utilizados na execução das atividades, descrição dos procedimentos e intervalo de tempo para monitoramento. Por meio dessa 
padronização, busca-se diminuir a incidência de desvios na realização das tarefas.

De forma indireta o procedimento operacional padrão também atuará sobre a perecibilidade dos alimentos e as condições das gôndolas, pois nele também estará discriminada a forma e a frequência de higienização. $O$ processo de higienização apropriado é importante para diminuir as condições favoráveis para o desenvolvimento de microrganismos e evitar a deterioração e/ou contaminações nestes alimentos, esse processo deve ser realizado em um determinado intervalo de tempo, utilizando produtos químicos que tem por função limpar as superfícies e sanitizá-las.

O intuito da proposta de avaliação de fornecedores é diminuir ou eliminar as perdas/quebras derivadas da aquisição do produto, esta avaliação de fornecedores deverá ser feita por meio de um formulário, com atribuições de nota a cada requisito estabelecido pela empresa, os requisitos são condições básicas que devem ser atendidas pelo fornecedor para que ele esteja apto a fornecer seus produtos à referida empresa. A avaliação das entregas deverá ser feita periodicamente e registrado a sua conformidade de acordo com os requisitos exigidos pela empresa, a fim de analisar o desempenho individual de cada fornecedor e assim fazer uma triagem e ter subsídios para escolher aqueles que mais se adequam as exigências da empresa, é imprescindível que o fornecedor entenda seu papel e se adeque a padrão de qualidade necessitado pela empresa.
Com o desenvolvimento da previsão de vendas, pretende-se estabelecer a quantidade de $\mathrm{Kg}$ e/ou unidade necessário para atender de forma satisfatória os clientes e diminuir as perdas ocasionadas pelos pedidos maiores de compra em época de safra. Dessa forma, buscou-se determinar o índice de nível de serviço que melhor atendesse essas restrições, o nível de serviço analisa o estoque com ênfase em atender as demandas do mercado, estabelecendo assim uma porcentagem de grau de atendimento, pois quanto maior for o nível de serviço, maior será o custo com estoque.

Por meio de um diálogo com o gerente do supermercado, o qual tem uma melhor percepção das vendasdeterminou-se um nível de serviço de $80 \%$ para todos os produtos. A figura 6 apresenta o gráfico de nível de serviço $x$ quantidade necessária da laranja, nota-se que na medida em que aumenta o nível de serviço também ocorre o aumento da quantidade necessária, porém após os $80 \%$ a curva tem um aumento demasiado, tornando-se muito alto o custo para ter os níveis de serviços seguintes.

Com o desenvolvimento da previsão de vendas, pretende-se estabelecer a quantidade de $\mathrm{Kg}$ e/ou unidade necessário para atender de forma satisfatória os clientes e diminuir as perdas ocasionadas pelos pedidos maiores de compra em época de safra, como demonstra a Figura 6, representação gráfica para demanda diária do produto laranja. 
Figura 6. Demanda diária da laranja.

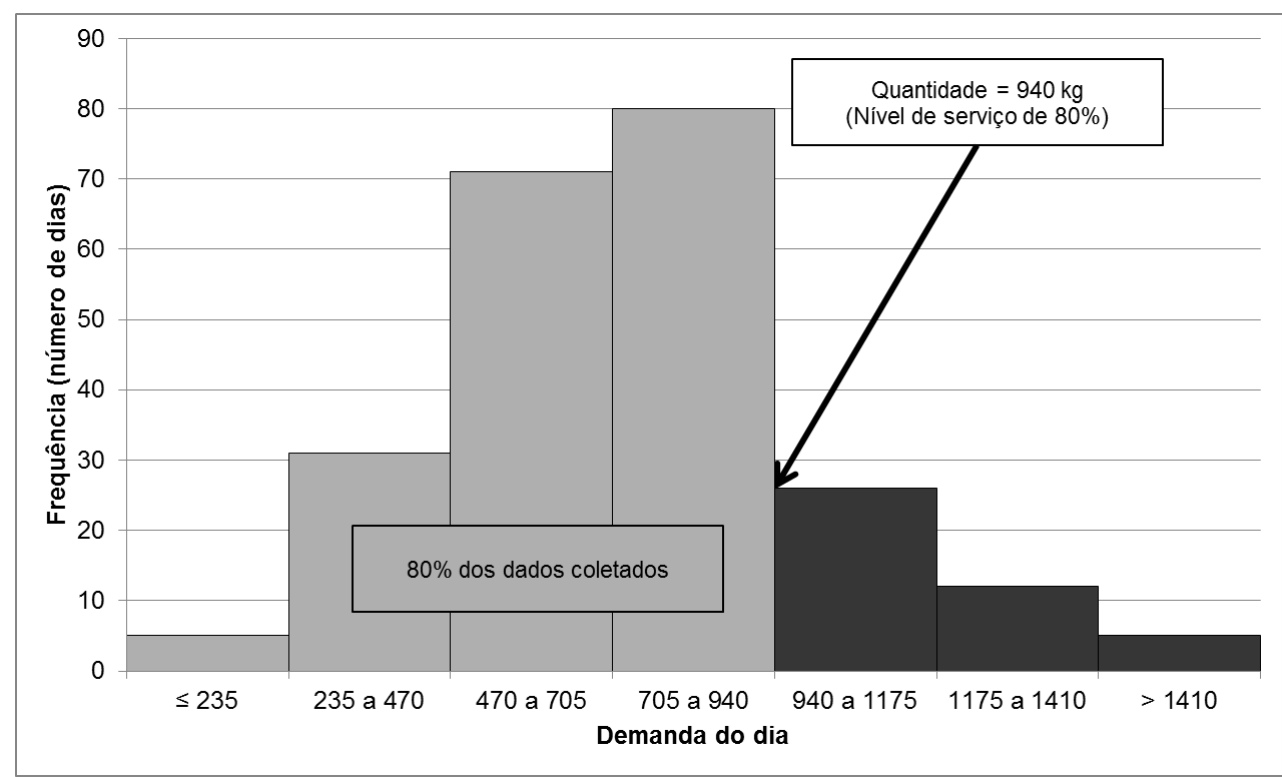

Fonte: OAutor.

\section{DISCUSSÃO}

Em resumo, os fatores que provocam ou auxiliam o aumento das quebras são o excesso de umidade relativa do ar, alta atividade de água característica do próprio alimento e oscilações na temperatura provocada pelas alterações climáticas devidas estações chuvosas e secas. Quando se trata de perdas ocasionadas pela ação do homem, estão relacionados o transporte em grandes distâncias, manuseio incorreto ou excessivo e acondicionamento não adequado, onde favorecem as ações do escurecimento enzimático devido a atuação das enzimas oxidantes.

No que se refere às práticas de controle de qualidade, o presente trabalho tem como proposta a implantação de procedimentos operacionais padronizados e avaliação de fornecedores a fim de eliminar ou minimizar as perdas do setor de hortifrúti do supermercado. A criação destes procedimentos irá orientar as sequências das atividades e a periodicidade de realização. Por meio dessa padronização, busca-se diminuir a incidência de desvios na realização das tarefas.

De forma indireta o procedimento operacional padrão também atuará sobre a perecibilidade dos alimentos e as condições das gôndolas, pois nele também estará discriminada a forma e a frequência de higienização. $O$ processo de higienização apropriado é importante para diminuir as condições favoráveis para o desenvolvimento de microrganismos e evitar a deterioração e/ou contaminações nestes alimentos, esse processo deve ser realizado em um determinado intervalo de tempo, utilizando produtos químicos que tem por função limpar as superfícies e sanitizá-las.

$\mathrm{O}$ intuito da proposta de avaliação de fornecedores é diminuir ou eliminar as perdas/quebras derivadas da aquisição do produto, esta avaliação de fornecedores deverá ser feita por meio de um formulário, com atribuições de nota a cada requisito estabelecido pela empresa, os requisitos são condições básicas que devem ser atendidas pelo fornecedor para que ele esteja apto a fornecer seus produtos à referida empresa. A avaliação das entregas deverá ser feita periodicamente e registrado a sua conformidade de acordo com os requisitos exigidos pela empresa, a fim de analisar o desempenho individual de cada fornecedor e assim fazer uma triagem e ter subsídios para escolher aqueles que mais se adequam as exigências da empresa, é imprescindível que o fornecedor entenda seu papel e se adeque a padrão de qualidade necessitado pela empresa. 
Através do histórico de vendas da laranja do primeiro semestre de 2015 e 2016, desenvolveu-se o gráfico de demanda do dia $x$ frequência (FIGURA 6). Ele expressa a quantidade de dias em que determinada demanda diária apresentou-se dentro do período estudado. Assim, a quantidade de laranja necessária para atender um nível de serviço de $80 \%$ é de $940 \mathrm{Kg}$ diários. Assim como para a laranja, foi feito uma previsão diária para todos os outros produtos que se enquadram dentro do nível de serviço de $80 \%$.

\section{CONCLUSÃO}

Com a aplicação das ferramentas da qualidade a fim de diagnosticar as origens do problema. Constatou-se que no primeiro trimestre de 2015 o setor teve uma quebra de $6,35 \%$ referente às vendas, no primeiro trimestre de 2016 teve 5,33\%, no segundo trimestre de 2015 foi de $5,21 \%$ e no segundo trimestre de 2016 foi de 5,11\%. Foi possível identificar os fatores que provocam ou auxiliam o aumento das quebras no setor de hortifrúti são: a alta perecibilidade dos alimentos, o método de abastecimento das gôndolas, a gestão de pedidos de compra, os manuseios inadequados dos alimentos, a seleção e qualificação dos fornecedores, o treinamento da equipe da seção, o transporte, a condição das gôndolas, os períodos de safra e os fatores climáticos.

Com a previsão de vendas obteve-se uma quantidade de pedido diário de 150 und de abacaxi hawai, $100 \mathrm{Kg}$ de abobora menina, $85 \mathrm{Kg}$ de banana maça, $450 \mathrm{Kg}$ de banana nanica, $80 \mathrm{Kg}$ de banana prata, $480 \mathrm{Kg}$ de batata extra, $134 \mathrm{Kg}$ de berinjela, $322 \mathrm{Kg}$ de caqui, $380 \mathrm{Kg}$ de cebola, $240 \mathrm{Kg}$ de cenoura, $132 \mathrm{Kg}$ de chuchu, $140 \mathrm{Kg}$ de goiaba, $940 \mathrm{Kg}$ de laranja, $72 \mathrm{Kg}$ de laranja lima, $250 \mathrm{Kg}$ de limão, $144 \mathrm{Kg}$ de maça fuji, $180 \mathrm{Kg}$ de maça gala, $252 \mathrm{Kg}$ de mamão formosa, $100 \mathrm{Kg}$ de mamão papaia, $60 \mathrm{Kg}$ de manga, $264 \mathrm{Kg}$ de melancia, $132 \mathrm{Kg}$ de pepino japonês, $114 \mathrm{Kg}$ de pera argentina willians, $201 \mathrm{Kg}$ de pêssego, $584 \mathrm{Kg}$ de poncan, $200 \mathrm{Kg}$ de repolho e $660 \mathrm{Kg}$ de tomate rasteiro.

\section{REFERÊNCIAS}

ABRAS.Varejistas perdem $2,89 \%$ da receita em ineficiências e roubos. 2015. Disponível em: $<$ http://www.abras.com.br/clipping.php?area=1\& clipping=53771 >. Acesso em: 30 mar. 2016.

BEZERRA, C. A. Técnicas de planejamento, programação e controle da produção e introdução à programação linear. Curitiba: InterSaberes, 2014. Disponível em: <http://unoeste.bv3.digitalpages.com.br/users/p ublications/9788582129876/pages/-2>. Acesso em: 08 maio 2016.

CHIAVENATO, I. Gestão de materiais: uma abordagem introdutória. 3. ed. Barueri, SP: Manole, 2014. Disponível em: $<$ http://unoeste.bv3.digitalpages.com.br/users/p ublications/9788520437995/pages/-12>. Acesso em: 12 maio 2016.

GOZZI, M. P. Gestão da Qualidade em Bens e Serviços. 2. ed. São Paulo: Person Education do Brasil, 2015. Disponível em: $<$ http://unoeste.bv3.digitalpages.com.br/users/p ublications/9788543010175/pages/-12>. Acesso em: 18 abr. 2016.

MELLO, C. H. P. Gestão da qualidade. São Paulo: Person Education do Brasil, 2011. Disponível em: $<$ http://unoeste.bv3.digitalpages.com.br/users/p ublications/9788576056997/pages/ 1>. Acesso em: 15 abr. 2016.

MENEZES, F. M. MASP Metodologia de Análise e Solução de Problemas. Porto Alegre: ABDI, 2013.

NACK, B. C. G. S.; BONFADINI, G. J. Gestão de compras na cadeia de suprimentos: analisando os fornecedores de itens classe $C$ (curva $A B C$ ). Revista Estudo \& Debate. Lajeado - RS, v. 20, n. 2, $2013 . \quad$ Disponível em: $<$ http://semanaacademica.org.br/system/files/art igos/artigo2.pdf>. Acesso em: 12 maio 2016.

SANTOS, A. P. L. Planejamento, programação e controle da produção. Curitiba: InterSaberes, $2015 . \quad$ Disponível em: $<$ http://unoeste.bv3.digitalpages.com.br/users/p ublications/9788544302828/pages/-2>. Acesso em: 08 maio 2016. 
SELEME, R.; STADLER, H. Controle da Qualidade: as ferramentas essenciais. 2. ed. Curitiba: Ibpex, 2010.

SIQUEIRA, J. C. Estratégias de compras: um fator primordial para o crescimento empresarial. Revista CientíficaSemana Acadêmica. Fortaleza, v. 1, n. 20, jul. 2013. Disponível em: $<$ http://semanaacademica.org.br/artigo/estrategi as-de-comprasum-fator-primordial-para-ocrescimento-empresarial>. Acesso em: 12 maio 2016.

SLACK, N.; CHAMBERS, S.; JOHNSTON, R. Administração da produção. 3. ed. São Paulo: Atlas, 2009.

VIEIRA, S. Estatística para a qualidade. 2. ed. Rio de Janeiro: Elsevier, 2012. 